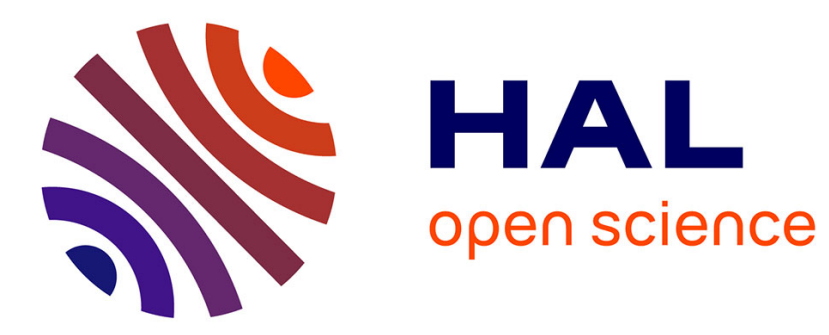

\title{
Experimental and numerical modelling of the ignition of solid propellant
}

\author{
R. Charlery, Mathieu Renouf, Aurélien Saulot, N. Daly, Yves Berthier
}

\section{To cite this version:}

R. Charlery, Mathieu Renouf, Aurélien Saulot, N. Daly, Yves Berthier. Experimental and numerical modelling of the ignition of solid propellant. Tribology International, 2015, 82, pp.330-342. 10.1016/j.triboint.2014.07.012 . hal-02093016

\section{HAL Id: hal-02093016 https://hal.science/hal-02093016}

Submitted on 8 Apr 2019

HAL is a multi-disciplinary open access archive for the deposit and dissemination of scientific research documents, whether they are published or not. The documents may come from teaching and research institutions in France or abroad, or from public or private research centers.
L'archive ouverte pluridisciplinaire HAL, est destinée au dépôt et à la diffusion de documents scientifiques de niveau recherche, publiés ou non, émanant des établissements d'enseignement et de recherche français ou étrangers, des laboratoires publics ou privés. 


\title{
Experimental and numerical modelling of the ignition of solid propellant
}

\author{
R. Charlery ${ }^{\mathrm{a}, \mathrm{c}, *,}, \mathrm{M}$. Renouf ${ }^{\mathrm{b}}$, A. Saulot ${ }^{\mathrm{a}}, \mathrm{N}$. Daly ${ }^{\mathrm{c}}, \mathrm{Y}$. Berthier ${ }^{\mathrm{a}}$
}

a LaMCoS, University of Lyon, CNRS, INSA Lyon, F-69621 Villeurbanne, France

${ }^{\mathrm{b}}$ LMGC, University of Montpellier 2, CNRS, F-34096 Montpellier, France

${ }^{\mathrm{c}}$ HERAKLES-SAFRAN Group, 91710 Vert-le-Petit, France

\section{A B S T R A C T}

Mixing processes of solid propellants can result in friction. Solid propellant ignitions can be observed under safety tests. Analysing a solid propellant elementary friction test from a mechanical, thermal, and physiochemical point of view, it appears that specific friction conditions allow the emergence of component flows in the solid propellant volume, readying the self-ignition. Numerical simulations of the solid propellant elementary friction test involve discrete elements to model these dynamic behaviours of the components within the contact.

Indeed, comparisons between experiments and simulations are performed on mechanical para-meters and on the evolution of the solid propellant components within the contact. Such comparisons exhibit qualitative and quantitative results by validating local parameters (adhesion), which make understand the solid propellant ignition scenario.

Keywords:

Solid propellant tribology

DEM-experiments coupling

Segregation

Hotspots

\section{Introduction}

Solid propellants are very sensitive compounds that explode because of different types of external stresses, such as contact pressure, temperature, shock or shearing [1]. They are used in different applications such as military devices (ammunitions and missiles), space launchers (Ariane 5 boosters and pyrotechnic devices), and automotive safety (inflator for airbag systems) [1].

Various studies have investigated the explosion of energetic materials for its applications. When rubbed against a rotating disk, local heating phenomena, called hot spots, can be observed within the energetic material [2]. These hot spots are mainly due to contacts between solid components contained in the solid propellant [3-5]. These solid components improve the shearing sensitivity of the energetic material when their melting point is higher than the ignition temperature of the energetic material [6]. This is even truer if the stress applied to the energetic material is more intense. To date, laboratory evidence showed that the ignition of an energetic material hardly occurs when it is rubbed between metallic bodies [5]. However, in the reality of industry, some ignition incidents occur when solid propellants are sheared

* Corresponding author at: LaMCoS, University of Lyon, CNRS, INSA Lyon, F-69621 Villeurbanne, France. Tel.: +33 4724372 45; fax: +334 78890980.

E-mail address: rudy.charlery@insa-lyon.fr (R. Charlery). between metallic bodies [7]. Indeed, during the manufacturing process of solid propellants in Twin Screw Extruders (TSEs), the working parts are made of metal: screws are made of a copperaluminium alloy and barrel elements are made of nitrided steel. TSEs are new continuous mixing devices used to manufacture new energetic solid propellant formulations [8,9].

Thus, with industrial safety concerns, going against laboratory evidence, the issue is to understand how a solid propellant ignites when sheared between two first bodies, whether metallic or not.

To make a step forward in this understanding, a combined experimental/numerical approach has been developed. From an experimental point of view, a pin-on-plate tribometer, called TriboME, has therefore been used to reproduce some of the conditions that favour the ignition of a solid propellant under friction conditions. With this type of device, the solid propellant ignition can be recorded simultaneously in infrared and visible domains and the associated contact forces can also be determined using a bi-axial sensor. Then a numerical approach based on Discrete Element Method (DEM) is used in view to offer or not the confirmation of the solid propellant rheology and to identify the role of local parameters such as cohesion forces and local friction factors between solid components of the solid propellant.

After a description of the TriboME device, the measured friction factor and associated videos of the solid propellant shearing test, the influence of system parameters on the solid propellant ignition is interpreted. Due to these system parameters and after-test 
observations obtained from this experimental approach, the numerical simulation of this friction test takes place. Results are analysed and compared to experimental ones.

\section{Material and methods}

\subsection{TriboME setup}

Coming from the normalised security test Julius Peters [10], the TriboME device is an instrumented pin-on-plate tribometer, Fig. 1, designed to ignite a solid propellant by friction of the pin on the plate.

Because of the transparency properties of the sapphire in visible and infrared domains, the pin is made of sapphire to enable the friction track observation during the friction test. The plate is made of the same different metallic materials as those of screws and barrel elements, contents in the Twin-Screw Mixer device (TSM): nitrided steel and copper-aluminium alloy, in order to be closer to the contact conditions encountered in the TSM.

In the philosophy of the tribological triplet [14] and considering the contact between the pin, the solid propellant and the plate, the sapphire pin and the metallic plate are called first bodies. The solid propellant, laid on the plate, is called the third body.

A normal force, $F_{Z}$, is applied through the pin to the solid propellant with a referenced weight fixed to a lever arm. A force sensor is added under the plate in order to record the normal and tangential forces $\left(F_{Z}, F_{Y}\right)$ undergone by the solid propellant, as the mobile first body is the plate.

As the aim of the setup is to track solid propellant ignitions (sparkle, explosion or smell and smoke), a test will be called positive if one of these phenomena is recorded, using two high speed-recording cameras simultaneously record infrared and visible videos of the friction test.

Owing to the TriboME device, both tangential and normal forces $\left(F_{Y}, F_{Z}\right)$ are then measurable during a solid propellant friction test. The referenced weight $(w=10.012 \mathrm{~kg})$, fixed on the sixth notch of the lever arm (Fig. 1), applies a vertical load $F_{Z}$ $(353 \mathrm{~N})$, characterised by a primary frequency $f_{z}$ equals to $15 \mathrm{~Hz}$. To highlight the ignition characteristics of the solid propellant in infrared and visible domains (explosion and temperature), suitable cameras are used: the VisionResearch high speed recording camera Phantom V710 (with a frequency of acquisition of $10,000 \mathrm{~Hz}$, a resolution of $240 \times 200$ pixel and an exposure time of $50 \times 10^{-9} \mathrm{~s}$ ) and the FLIR infrared camera Jade III MWIR (with a frequency of acquisition of $177 \mathrm{~Hz}$, a resolution of $340 \times 260$ pixel and an integration time of $20 \times 10^{-6} \mathrm{~s}$ ).

Due to the addition of this equipment (sensors and cameras) within the TriboME device, it is thus possible to study the

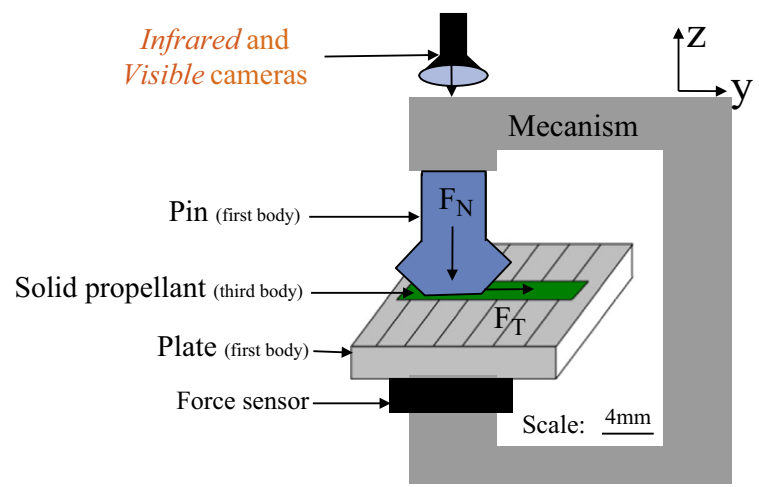

Fig. 1. TriboME device. preferential mechanical and thermal conditions for a solid propellant ignition.

\subsubsection{Test objectives}

After preliminary tests that aimed to define the influencing conditions that favour the ignition of a solid propellant when introduced between two friction first bodies, the following tests are set to highlight these conditions. These depend on:

- The mechanism (the TriboME device): friction acceleration, friction factor, etc...

- The first bodies (pins and plates): the nature of the material.

- The third body (the solid propellant): motions of the solid propellant components.

\subsubsection{Test conditions}

One cycle test is a one-way sliding motion of $10 \mathrm{~mm}$, applied by the plate (an acceleration-deceleration motion, Fig. 3) and separated into five phases.

\subsection{Specimens: First and third bodies}

\subsubsection{Pin and plate: First bodies}

First of all, some solid propellant ignitions are observed in twin-screw extruders [7] that use metallic working parts:

- Barrel elements are made of nitrided steel.

- Screws are made of a copper-aluminium alloy.

In order to study the influence of the mechanism of the TriboME device at its boundary limits on the solid propellant tribological response $\left(V_{\text {plate } \max }=66 \mathrm{~mm} \mathrm{~s}^{-1}\right.$ and $\left.F_{Z \text { max }}=353 \mathrm{~N}\right)$, metallic first bodies are also used in this study (Fig. 2a-d).

Next, the standard NF T 50370 fixes the geometries and the dimensions of the porcelain first bodies [10], Fig. 2e and f. These first bodies are the reference ones because all the energetic materials are tested with these ones in the literature $[1,10]$ :

- striated porcelain plate: $25 \mathrm{~mm}$ long, $25 \mathrm{~mm}$ width and $5 \mathrm{~mm}$ thick

- striated porcelain pin: radius of $R_{y}=5 \mathrm{~mm}$ and a radius of curvature of $R_{z}=10 \mathrm{~mm}$

Metallic specimens are machined from the same materials as the working parts of the twin-screw extruder. Both dimensions and geometries are the same as those made of porcelain, except for the plate width:

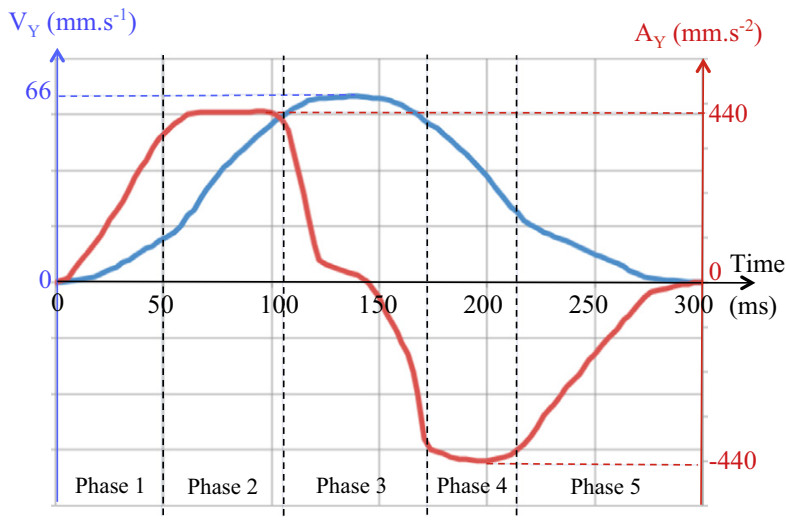

Fig. 2. Plate speed $(V Y)$ and plate acceleration $(A Y)$ variations on the TriboME device. 
- striated metallic plate: $25 \mathrm{~mm}$ long, $15 \mathrm{~mm}$ width and $5 \mathrm{~mm}$ thick

- striated metallic pin: radius of $R_{y}=5 \mathrm{~mm}$ and a radius of curvature of $R_{z}=10 \mathrm{~mm}$.

Therefore, in order to study the influence of both the material nature and the surface roughnesses on the solid propellant ignition, four types of materials are tested:

- a porcelain grade

- an alloyed copper-aluminium grade

- a nitrided steel grade

- a mirror-finish sapphire

The mechanical properties and the geometries of each first body are presented in Table 1 and Fig. 2.

Triplets of materials are organized as follows:

- Triplet 1: Striated porcelain pin/solid propellant/striated porcelain plate.

- Triplet 2: Striated copper-aluminium alloy pin/solid propellant/striated nitrided steel plate.

Table 1

Mechanical properties of the constitutive materials of the first bodies.

\begin{tabular}{lccc}
\hline Materials & $\begin{array}{l}\text { Knoop } \\
\text { hardness }\end{array}$ & $\begin{array}{l}\text { Young's modulus of } \\
\text { elasticity (GPa) }\end{array}$ & $\begin{array}{l}\text { Compressive } \\
\text { strength (MPa) }\end{array}$ \\
\hline $\begin{array}{l}\text { Copper- } \\
\quad \text { aluminium }\end{array}$ & 153 & 125 & 950 \\
$\quad$ alloy & & & \\
Nitrided steel & 800 & 210 & 1200 \\
Porcelain & 550 & 72 & 700 \\
Sapphire & 2200 & 400 & 2000 \\
\hline
\end{tabular}

- Triplet 3: Striated nitrided steel pin/solid propellant/striated nitrided steel plate.

- Triplet 4: Smooth nitrided steel pin/solid propellant/striated nitrided steel plate.

- Triplet 5: Smooth copper-aluminium alloy pin/solid propellant/smooth nitrided steel plate.

- Triplet 6: Sapphire pin/solid propellant/striated porcelain plate.

The metallic surface roughnesses, obtained by milling operation, are $R_{\mathrm{a} 1}=0.4 \mu \mathrm{m}$ (smoother surface) and $R_{\mathrm{a} 2}=2 \mu \mathrm{m}$ (less smooth surface) for pin specimens and $R_{\mathrm{a} 1}=0.4 \mu \mathrm{m}$ and $R_{\mathrm{a} 3}=11 \mu \mathrm{m}$ (surface roughness provide for by standard NF T 503 70) for plate specimens. The surface roughness $R_{\mathrm{a} 1}$ matches the machine-finish surface roughness of the working parts in a twin-screw extruder. The surface roughness $R_{\mathrm{a} 2}$ represents the surface roughness of a hypothetical damaged surface of a working part in a twin-screw extruder.

Milling marks are oriented perpendicularly to the shearing direction.

In order to eliminate pollution residues due to the machining and handling of the first bodies, both pins and plates are mechanically "cleaned" by ultrasound and chemically "cleaned" in an ethyl-acetate bath for $5 \mathrm{~min}$. Then rinsing is done in an ethanol bath. Finally, these are dried to eliminate the residue of ethanol that potentially gets trapped in the porosities of the specimens.

Five consecutive tests are realized for each triplet of materials.

\subsubsection{Solid propellant: The third body}

As previously said, the energetic material tested in this study is a solid propellant. It is the third body in the contact. It is a heterogeneous material, as it has different types of components. The main components found in this solid propellant are:
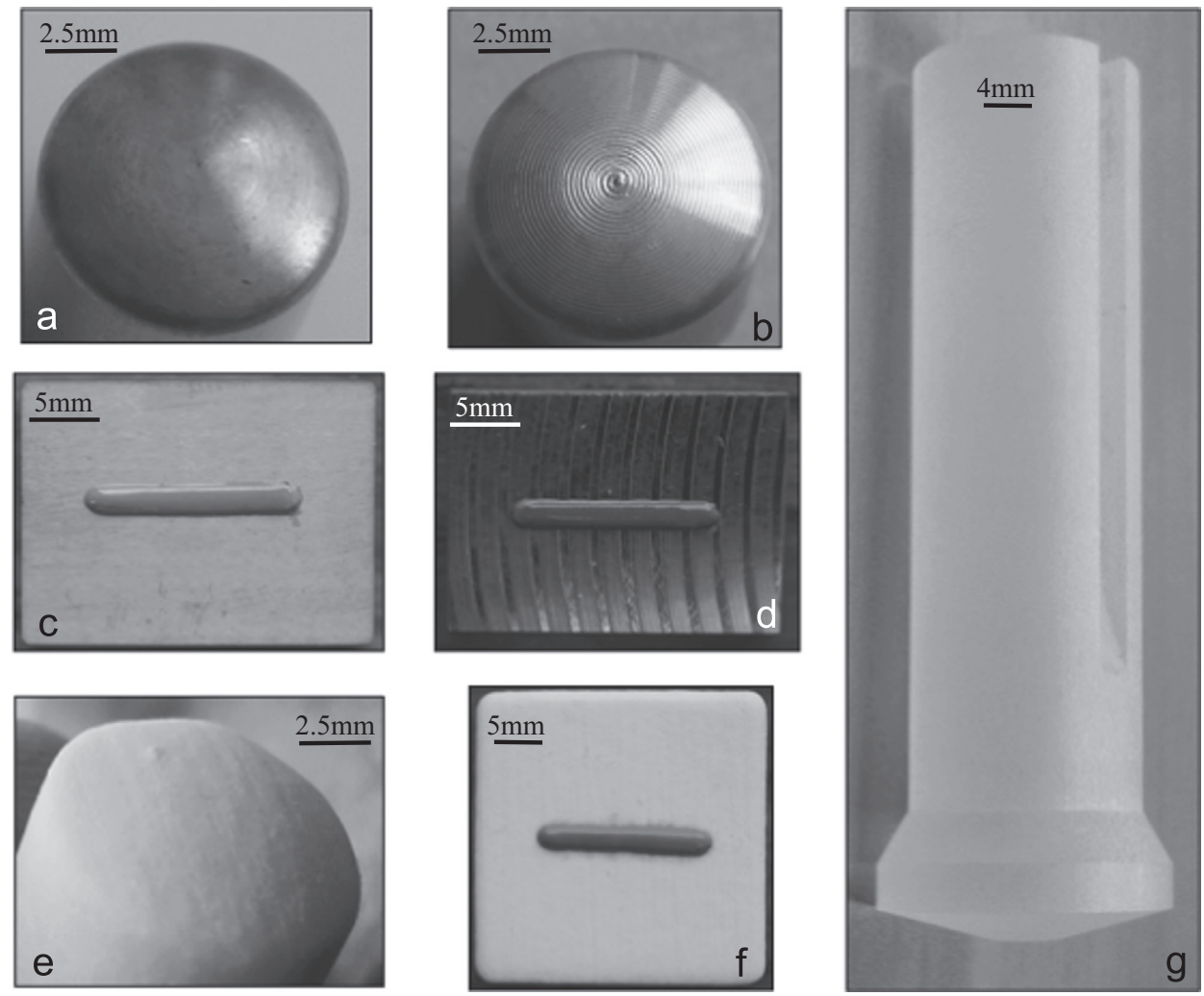

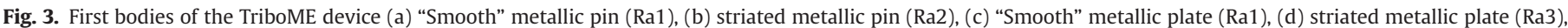
(e) striated porcelain pin (Ra3), (f) striated porcelain plate (Ra3), (g) sapphire pin. 
- A binder: polymer + nitrided esters, referred to as fluid components in this study.

- Nitramine solid components: solid components with larger $\left(\varnothing_{+}\right)$and smaller $\left(\varnothing_{-}\right)$diameter.

- Oxidizer solid components: solid components with larger $\left(\emptyset_{+}\right)$ diameter.

- Reducer solid components: solid components with smaller ( $\left.\varnothing_{-}\right)$ diameter.

In this study, the same solid propellant formulation is used in all tests.

\section{Experimental approach}

\subsection{Optical observations of a solid propellant ignition}

As the recorded solid propellant ignition is an explosion, the pictures taken from the recorded videos of each triplet of materials are quite the same. As a consequence, only the pictures of the Triplet 3 are presented in this part, Fig. 3:

During phase 1, the acceleration of the plate, $A_{Y}$, increases from 0 to $440 \mathrm{~mm} \mathrm{~s}^{-2}$. In phase 2 , the acceleration of the plate is stabilized at its maximum absolute value $\left(\left|A_{Y}\right|=440 \mathrm{~mm} \mathrm{~s}^{-2}\right)$ between $55 \mathrm{~ms}$ and $105 \mathrm{~ms}$. At $80 \mathrm{~ms}$ a first solid propellant ignition is observable. Then a sharp drop of the plate acceleration occurs during phase 3 , between 105 and $170 \mathrm{~ms}$. As for phase 2 during phase 4 , the plate acceleration stabilised at its maximum absolute value $\left(\left|A_{Y}\right|=440 \mathrm{~mm} \mathrm{~s}^{-2}\right.$, obtained between 170 and $220 \mathrm{~ms}$ ). At $230 \mathrm{~ms}$, a second solid propellant ignition is observable. Finally in phase 5 the plate acceleration returns to the initial zero value.

Consequently, it is interesting to analyse the mechanical stresses, i.e. the evolution of the friction factor, applied during the friction test and recorded by using the biaxial force sensor.

\subsection{Mechanical conditions of a solid propellant ignition}

The first triplet of materials tested is the Triplet 1 (Porcelain pin/solid propellant/porcelain plate).
As a biaxial force sensor records the tangential and normal forces, it is thus possible to measure the friction factor as the ratio between $F_{Y}$ and $F_{Z}$, during the friction test. It evolves in five phases (Fig. 4):

- Phase A: increase of the friction factor $(\mu)$ from 0 to its average value $(\mu=0.04)$.

- Phase B: fluctuations of the friction factor $(\mu)$, between its minimum $(\mu=0.01)$ and maximum values $(\mu=0.13)$

- Phase C: stabilization of the friction factor at its average value (between 100 and $200 \mathrm{~ms}$ ).

- Phase D: fluctuations of the friction factor $(\mu)$, between $\mu=0.03$ and $\mu=0.09$.

- Phase E: return to its initial zero value $(\mu)$.

The same trend for friction factor instabilities is observed for other triplets of materials, i.e. during the same time phases, the same friction factor instabilities are observed.

This means that more importantly than the difference in nature of the materials of the first bodies and the friction factor average value, the friction factor instabilities has an influence on the solid propellant ignition. The more the friction factor fluctuates, the more the solid propellant ignition probability increases.

After having considered these mechanical conditions that allow solid propellant ignitions to be obtained, the thermal conditions and phenomena that occur during the friction test are studied.

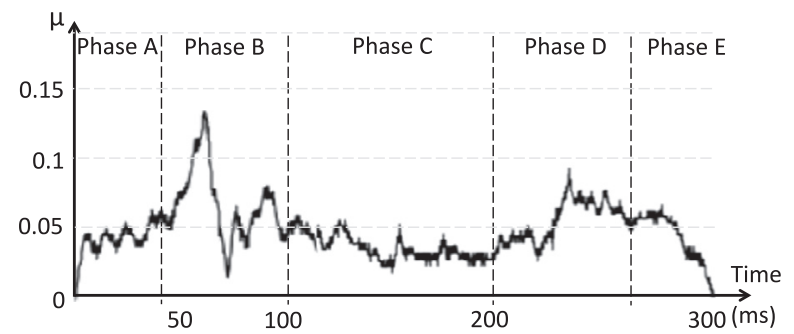

Fig. 5. Friction factor evolution during the friction test.

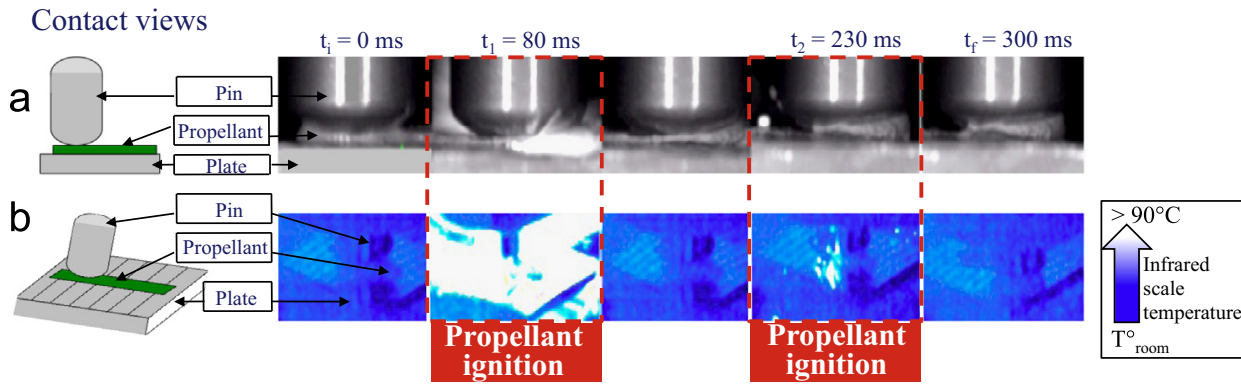

C

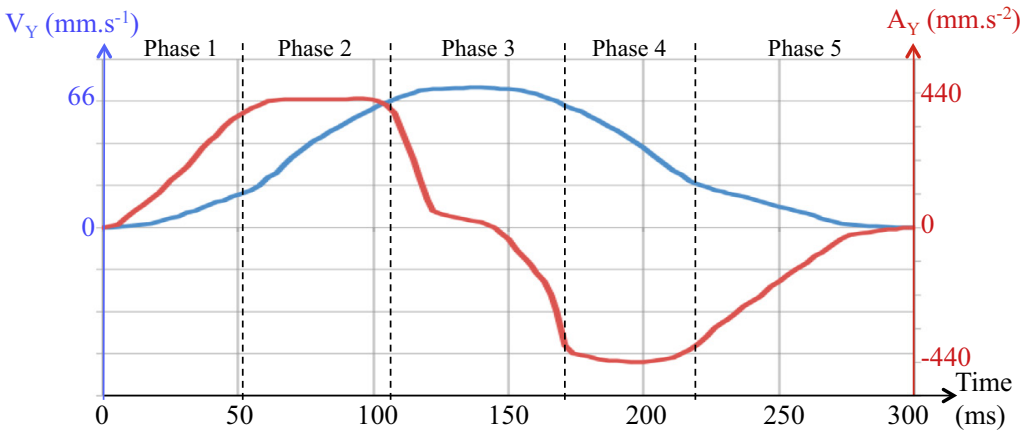

Fig. 4. (a) Visible pictures recorded during the friction test of the solid propellant, (b) infrared pictures recorded during the friction test of the solid propellant, (c) plate speed $(V Y)$ and plate acceleration $(A Y)$ variations during the friction test of the solid propellant. 


\subsection{Thermal conditions of a solid propellant ignition}

According to all the types of nature of materials and geometries that are tested, different responses of the tested solid propellant are expected: generalised ignitions and localised ignitions. Generalised ignitions have been presented in Fig. 5. The so-called localised ignitions are the hot spots [2]. Their lifetime has been evaluated at $2 \times 10^{-5} \mathrm{~s}$ [2]. As localised ignitions are within the contact, this is why a sapphire pin is used to study the friction test of a solid propellant. The goal of this part is to highlight when the solid propellant ignition probability is increased, and where hot spots appear in the friction track. To achieve that, the Triplet 6 is studied, because of the transparency properties of the sapphire pin:

- Sapphire pin/solid propellant/striated porcelain plate.

Due to the high-speed recording infrared camera, the friction track temperature is followed, Fig. 6.

Two peaks of temperature $\left(T=216^{\circ} \mathrm{C}\right)$, measured on the friction track, appear at 74 and $227 \mathrm{~ms}$. Between these two peaks, and after these two peaks, the friction track temperature stays at the ambient temperature, which is the temperature of the testing room, $T=21^{\circ} \mathrm{C}$.

It is deduced that, with these tribological conditions, the friction test does not induce a temperature increase of the friction

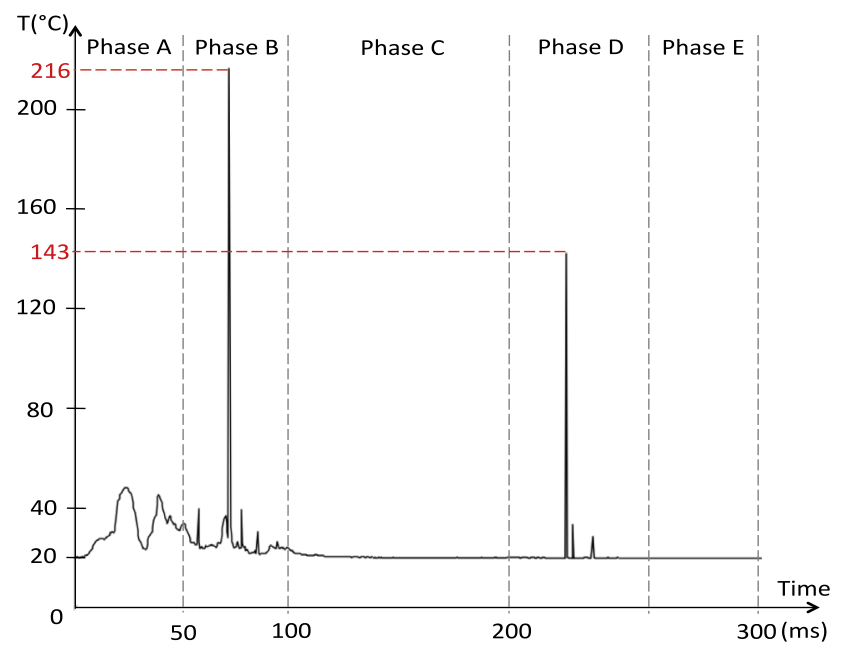

Fig. 6. Evolution of the friction track temperature during the friction test of the Triplet6. track, except for two specific sections, phases B and D, during which the friction factor fluctuates significantly.

The pictures taken from the Triplet 6 friction test confirm this, Fig. 7:

Two generalised ignitions (at $80 \mathrm{~ms}$ and $230 \mathrm{~ms}$, Fig. 7) and hot spots (at $11 \mathrm{~ms}$, Fig. 8) are observed within the friction track. These thermal phenomena occur during the time phases $\mathrm{B}$ and $\mathrm{D}$, when peaks of temperature (Fig. 6) and important fluctuations of the friction factor are observed (Fig. 4).

As a consequence, it is deduced that the two peaks of temperature observed at the solid propellant surface, are not induced by a continuous increase of the temperature of the entire friction track, but by internal phenomena within the solid propellant. These internal phenomena cause important friction factor fluctuations and have localised consequences (hot spots) or generalised ones (generalised ignition). Thus, these internal phenomena are related to motions of the solid propellant components during the friction tests. This study is achievable due to post-test analysis of the friction track by Optical Microscopy (OM) and Scanning Electron Microscopy (SEM).

\subsection{Post-test analysis of the friction track}

In order to understand the friction factor fluctuations and temperature peaks appearing during specific time phases, it is necessary to analyse the solid propellant behaviour within the friction track, and more precisely its components arrangements, during the friction test.

Each friction test is associated with a solid propellant tribological response characterised by a solid propellant (localised or generalised) ignition. This response is the consequence of a specific behaviour of the solid propellant under friction conditions. To highlight this behaviour, surface observations are carried out on the solid propellant samples from each triplets of materials using the SEM. As all the friction tracks in each triplet of materials present the same features, only the friction track of Triplet 6 is described in this study.

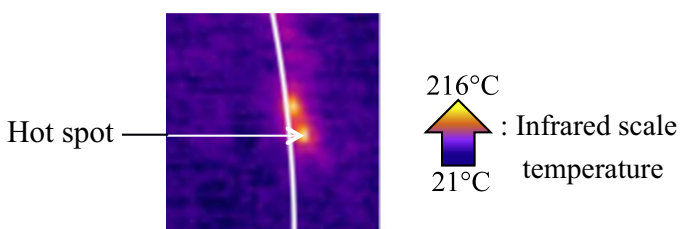

Fig. 8. Focus on hot spots observed at the boundary of the contact area, within the friction track, at $11 \mathrm{~ms}$, for the Triplet6.
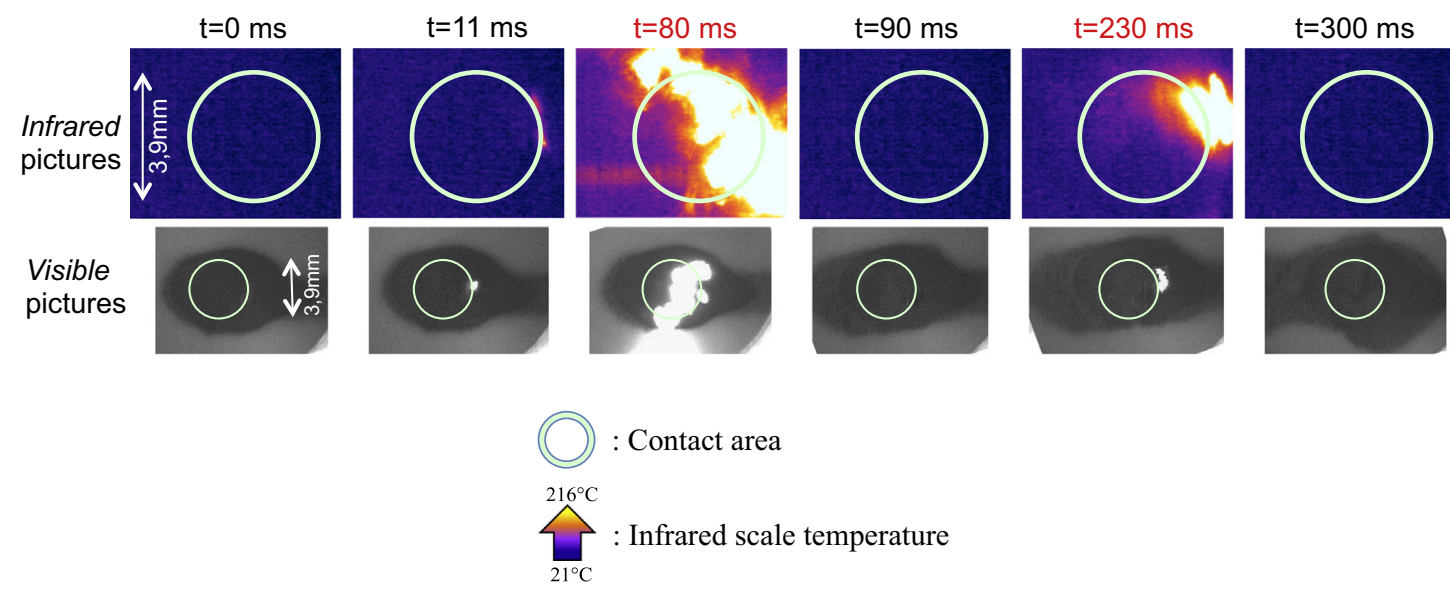

Fig. 7. Infrared and visible pictures recorded during the friction test of the Triplet6. 
The chemical map of the friction track is obtained by the Energy Dispersive X-ray spectrometry analysis (EDX) [16]. In the EDX pictures, the reducer solid components are blue-coloured (sphere-like), the oxidizer solid components are green-coloured (potato-like) and the nitramine solid components are red-coloured (potato-like). The reducer and the oxidizer components have their own distinctive atom, as opposed to the nitramine components whose atoms are similar to those of the binder (made of the polymer and nitrided oils).

\subsection{General overview of the friction track}

A first macroscopic observation is carried out before and after the friction test. Before the friction test, the solid propellant sample has a homogeneous aspect (Fig. 9a and b), as the components are equally distributed in the solid propellant volume. After the friction test, the solid propellant sample has a heterogeneous aspect (Fig. 9c) with a matt-coloured Section in the friction track and a shiny Section outside the friction track. The shiny Section mainly consists of fluid components (the polymer and nitrided oils) whereas the matt-coloured section mainly consists of solid components, Fig. 9d. This highlights the first component selection during the friction test with fluid components ejected out of the friction track, because of their lower viscosity, and dragging a smaller volume of solid components.

This component selection is called "fluid/solid" Segregation: Seg fluid/solid.

Five distinctive phases in the plate acceleration evolution have been identified previously (Fig. 4-6). As the plate acceleration evolution is symmetrical during the $300 \mathrm{~ms}$ of the friction test (Fig. 2), it has been decided to show the study of the first three sections of the friction track only, Fig. 10a, as the friction track sections match the time phases determined previously.

Section 1: This section corresponds to the beginning of the friction track (Fig. 11a). It is also the loading section.
Due to the EDX analysis (Fig. 11a), it is possible to validate that most of the solid components remaining in the centre of the friction track are the reducer components (blue-coloured) and the smaller nitramine components (red-coloured). The larger solid components, i.e. oxidizer components (green-coloured) and larger nitramine components (red-coloured), are at the periphery of the friction track.

This is the second component selection with most of the larger solid components ejected out of the friction track whereas smaller solid components stay in the centre of the friction track (the reducer component and the smaller nitramine component), Fig. 11b.

This component selection is called "solid/solid" Segregation: $\mathrm{Seg}_{\text {solid/solid, }}$ as it occurs before the friction test, during the loading phase, and in the first Section 1 of the friction track

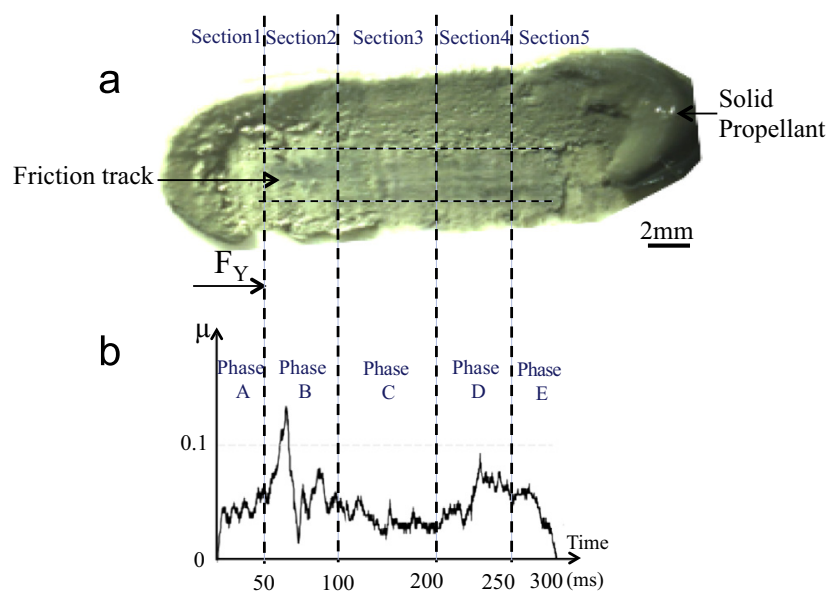

Fig. 10. Separation of the friction track in 5 sections, after the friction test (a) observation of the friction track by $\mathrm{OM}$, (b) friction factor evolution during the friction test.

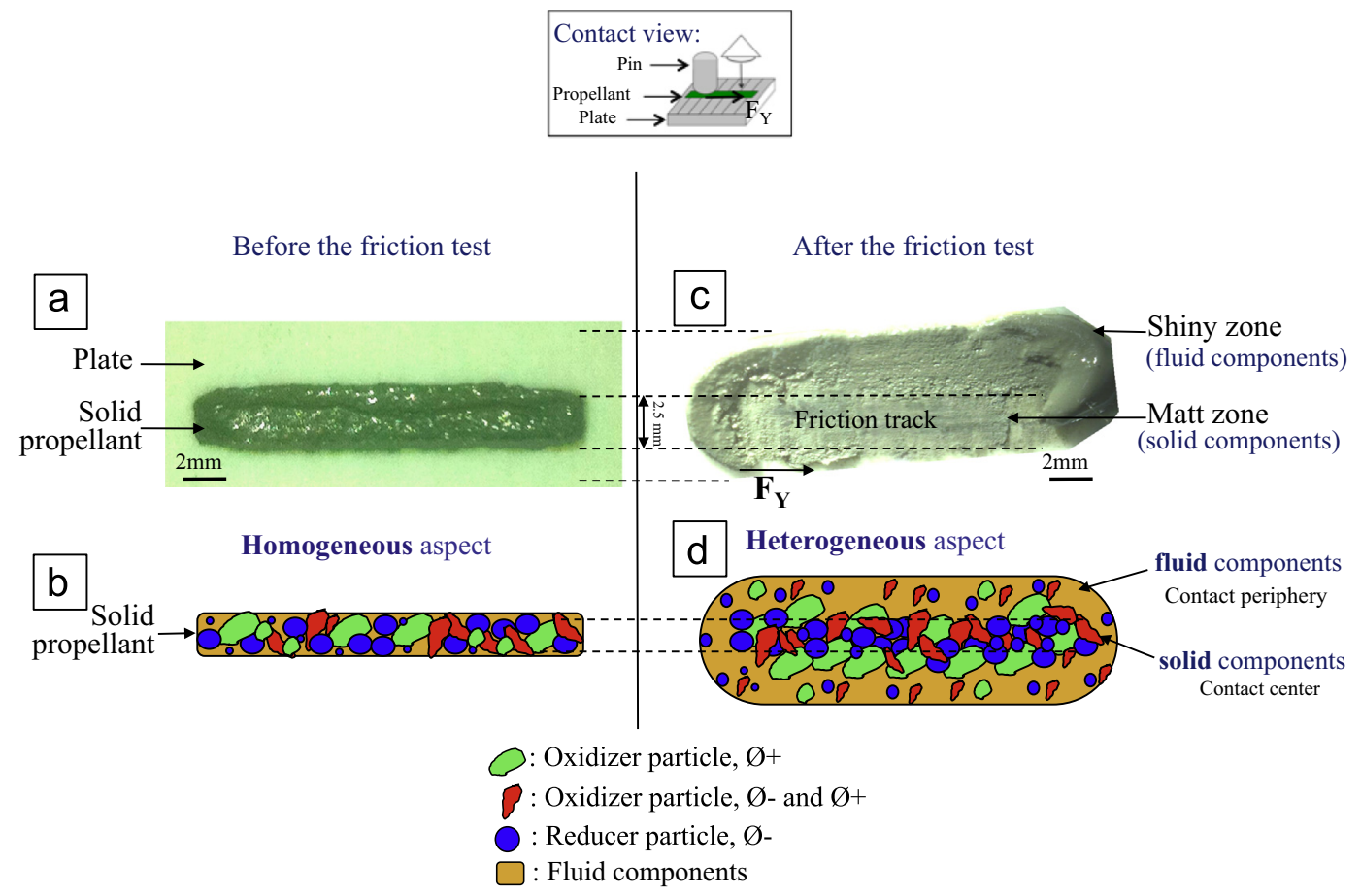

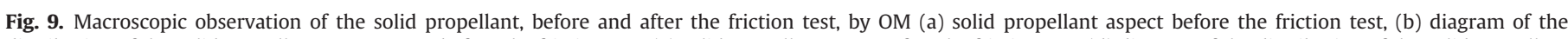

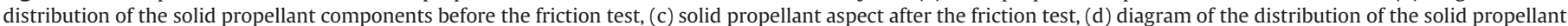
components after the friction test. (For interpretation of the references to color in this figure legend, the reader is referred to the web version of this article.) 
Section 2: This section comes next and presents the highest plate acceleration value $\left(A_{Y \max }=440 \mathrm{~mm} \mathrm{~s}^{-2}\right)$. A very compact layer, with cracks $[21,22]$, can be observed on the solid propellant surface (Fig. 12a). By focusing on a crack (Fig. 12b), it can be seen that such a layer is made of solid components similar in shape. With the EDX side view of this crack (Fig. 12c), it is deduced that this layer is mainly made of the smaller solid components: the reducer components and the smaller nitramine components. There, as shown by the $Z$-Contrast view (material contrast) of this layer (Fig. 12d), these solid components of the extreme surface undergo plastic deformations.

As some subsurface layers are observable on Fig. 12c, it is deduced that a Z-axis components selection occurs in Section 2. It is a consequence of an internal flow of residues of fluid components along the $Z$-axis (Fig. 12e). This flow rises from the subsurface to the extreme surface and it is a smaller solid components vector. It makes this extreme surface even more compact.

This is the third components selection during the friction test of the solid propellant.

It is called "plasticizing" Aggregation, because of the plastic deformation of some solid components, $\mathrm{Ag}_{\text {plast }}$. This aggregation gives rise to the Upper-layer, which is a "solid-like" layer [11,15,18-20].

Deeper in the volume of the solid propellant, an Intermediatelayer is determined, where residues of larger solid components (oxidizer and larger nitramine components) can be "stored" (Fig. 12b,d,e). Therefore this layer is mainly made of these larger solid components. This Intermediate-layer can be considered as a "liquid-like" layer $[11,15,18-20]$ because, there, larger solid components move easily as a lot of the smaller solid components have been transported to the Upper-layer. This Intermediate-layer is much less compact than the Upper-layer (Fig. 12b,d,e).

Finally, a more compact Lower-layer is determined. It is made of smaller solid components, i.e. reducer and smaller nitramine components (Fig. 12b,c,e), which are plastically deformed.

Section 3: Finally, this section, mainly located in the middle of the friction track, presents many crystals on the extreme surface of the Upper-layer (Fig. 13a and b), after the friction test.

As previously described in Section 2, fluid components are smaller particle vectors (12) and tend to rise from the Intermediate-layer to the extreme surface of the solid propellant sample during the friction test $\left(\mathrm{Ag}_{\text {plast }}\right)$.
In this Section 3, the $\mathrm{Ag}_{\text {plast }}$ still exists and a fluid film is observed on the extreme surface (Fig. 14a and b). The fact that with the SEM on EDX Mode the same chemical element characterizes the oxidizer solid components and the partially crystallized fluid on the extreme surface shows the relative fluid components solubility of oxidizer components (Fig. 13c and Fig. 14c).

After ageing of the solid propellant sample, the fluid film crystallization continues and the film turns to scattered crystals on the extreme surface (Fig. 14a).

Therefore, the excess of fluid components gives rise to a fluid film (Fig. 13d) that crystallizes as crystals in layer.

This fluid film that appears in the Section 3 of the friction track during the friction test, may lubricate the contact between the pin and the solid propellant and locally desensitizes the solid propellant.

As a consequence, to increase the probability to ignite the solid propellant with this friction test, a minor part of the fluid components has to be present in the friction contact (before the origination of a fluid film on the extreme surface) and a major part of the solid components has to be in the friction contact.

In order to validate this scenario that ignites the solid propellant by friction (Seg fluid/solid, $_{\text {Seg }}$ solid/solid, $\mathrm{Ag}_{\text {plast }}$ ), a more internal view of the contact, which disrupts it less, is required. In that respect, the Discrete Element Modelling is the more accurate method.

\section{Numerical approach}

Main observations have been performed with the experimental approach: localised ignitions and segregation of components. The main issue is that such phenomena are deeply related and their separation from an experimental point of view is tricky (13). To progress with the comprehension of the interlinking of previous phenomena, a numerical approach is used. In order to study the contact between the solid propellant and the first bodies, i.e. the setup of the solid components segregation and aggregation, and the influence of local parameters, such as cohesion between solid components, at a smaller scale, the choice of a Discrete Element Method (DEM) approach has been made [25], (26) to model the third body (the solid components of the solid propellant). In a first

a

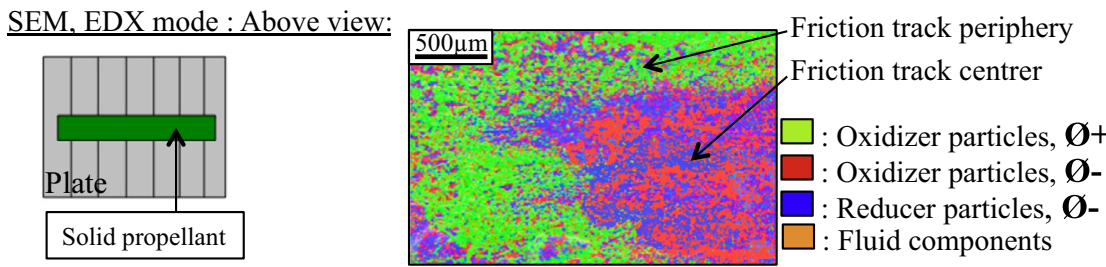

b

Chemical scheme: view from behind:

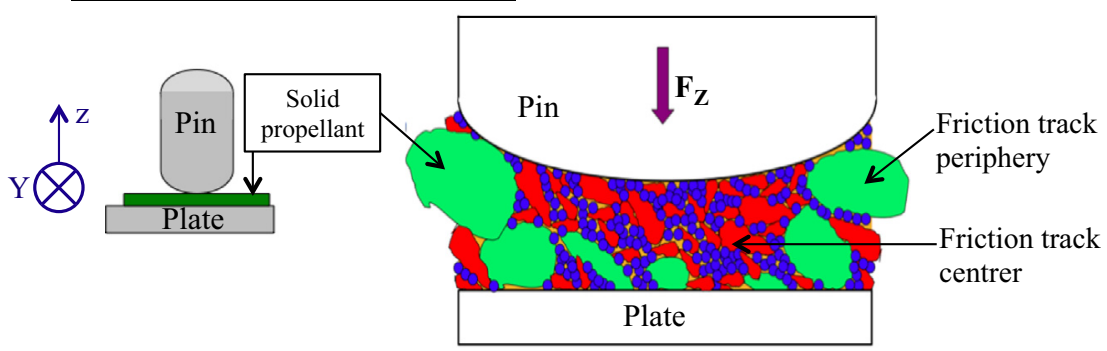

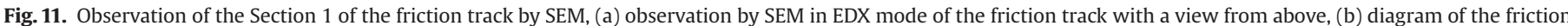
track with a view from behind. (For interpretation of the references to color in this figure legend, the reader is referred to the web version of this article.) 


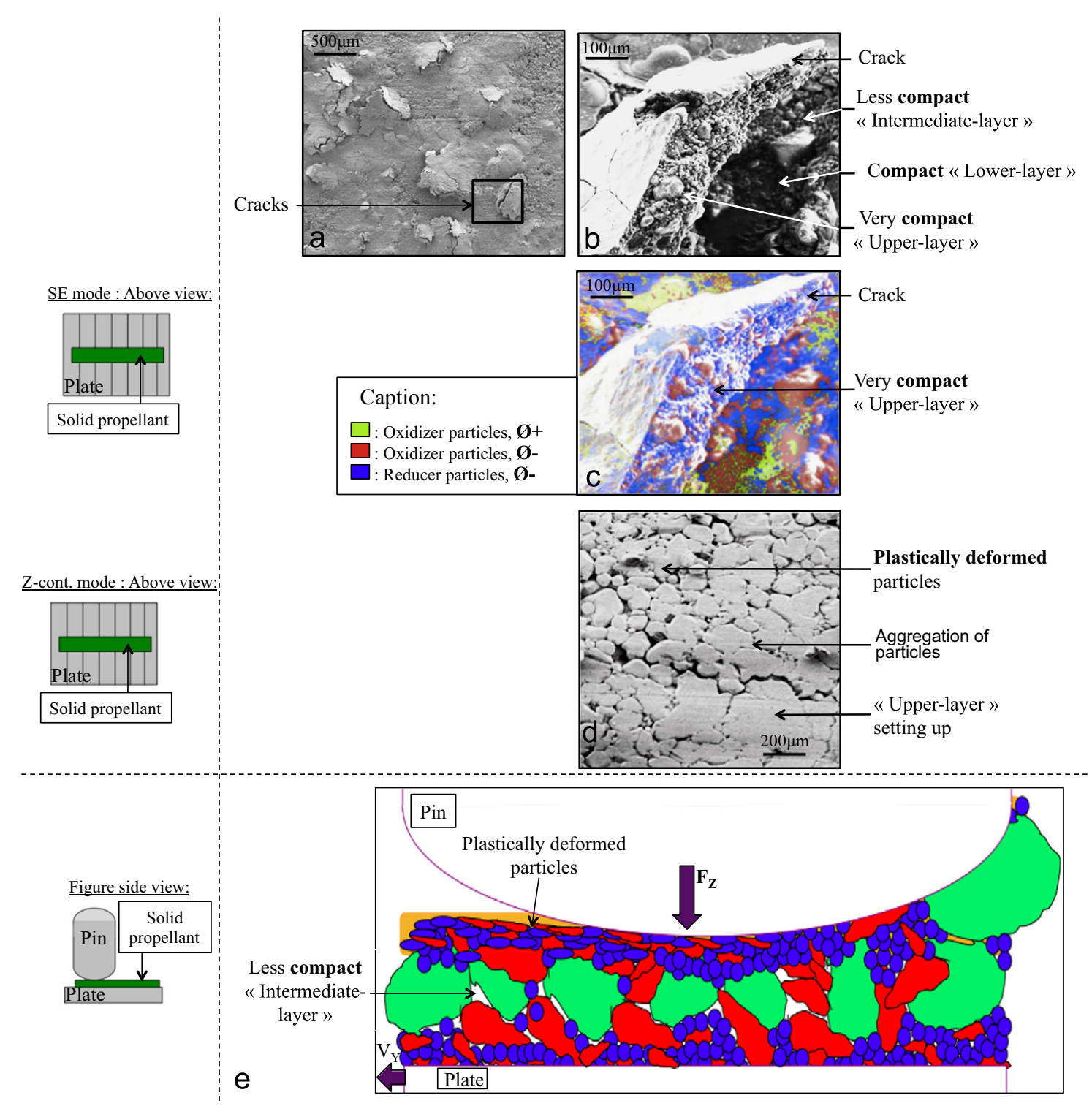

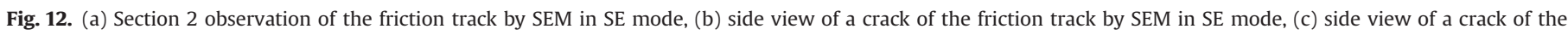

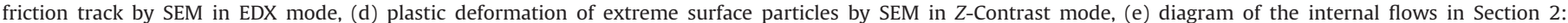
"plasticizing" Aggregation (Agplast).

approach, the fluid part is taken into account implicitly through interaction laws between particles.

Among the different DEM approaches available in the literature, the Non Smooth Contact Dynamics method (NSCD) developed by Moreau and Jean $[17,18]$ is used here. This approach has already been used for mechanical $[12,13]$ as well as for tribological applications $[19,20]$. Only the outlines of the approach are presented here, and the reader may refer to dedicated papers for more details $[24,25]$.

The key point in this numerical approach is to define the interaction law relating local contact forces, denoted $r$, and the relative velocity vectors, denoted $v$. Several laws are found in the literature, based on smooth or

non-smooth assumptions. According to previous numerical tribological studies, a non-smooth cohesive contact law is used to describe the normal part of the contact force combined to a Coulomb friction law to describe the tangential part. The first one involves a cohesion force threshold, denoted gamma, while the second one involves a local friction coefficient $\mu$.
The system (1) summarises the previous laws:

$$
\begin{cases}\left(r_{n}+\gamma\right) \geq 0, u_{n} \geq 0, & \left(r_{n}+\gamma\right) \cdot u_{n}=0 \\ \text { If } u_{t}=0 & \text { then }\left|r_{t}\right| \leq \mu r_{n} \\ & \text { else } r_{t}=-\operatorname{sign}\left(u_{t}\right) \mu r_{n}\end{cases}
$$

where the indices $n$ and $t$ refer to the normal and tangential parts of the considered vector.

To describe the different interactions in our model, two sets of parameters are used. The first one concerns the contact between the larger particles and other bodies (rough walls and smaller particles). A classic unilateral contact law coupled with a Coulomb friction model is used, involving only the friction coefficient $\mu$ as a parameter.

The second one concerns the contact between different discrete elements, between particles and the rough walls, and between the particles themselves. No information can be directly obtained to fix such law. Nevertheless, it is possible to interpret the phenomenology within the contact according to post-test 
a

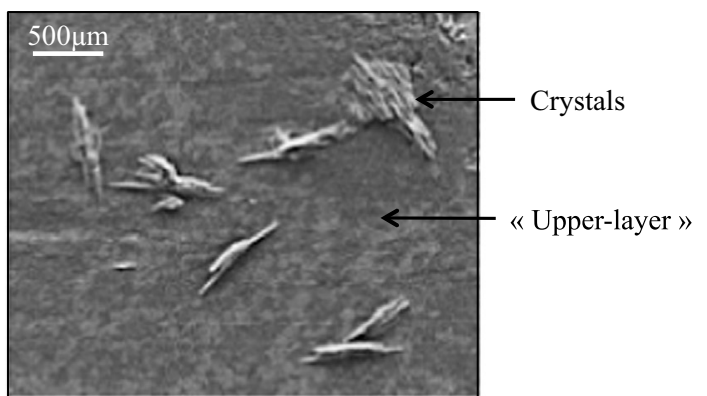

b

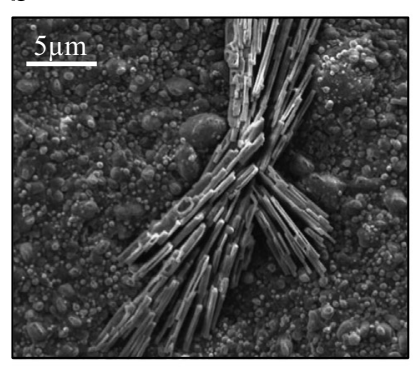

C

d
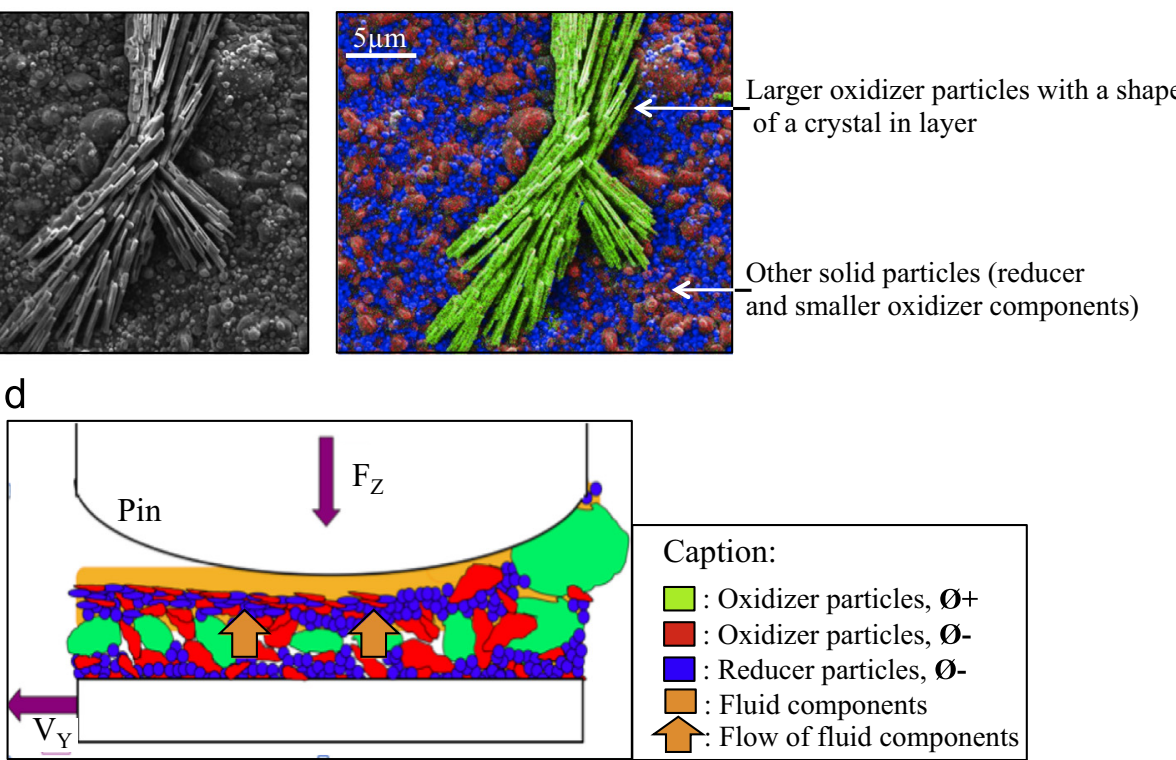

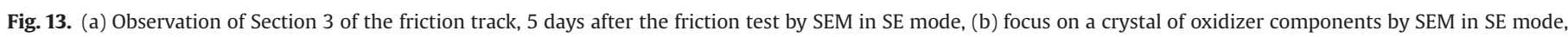
(c) focus on a crystal of oxidizer components by SEM in EDX mode, (d) chemical scheme of the internal arrangements of solid components in Section 3.

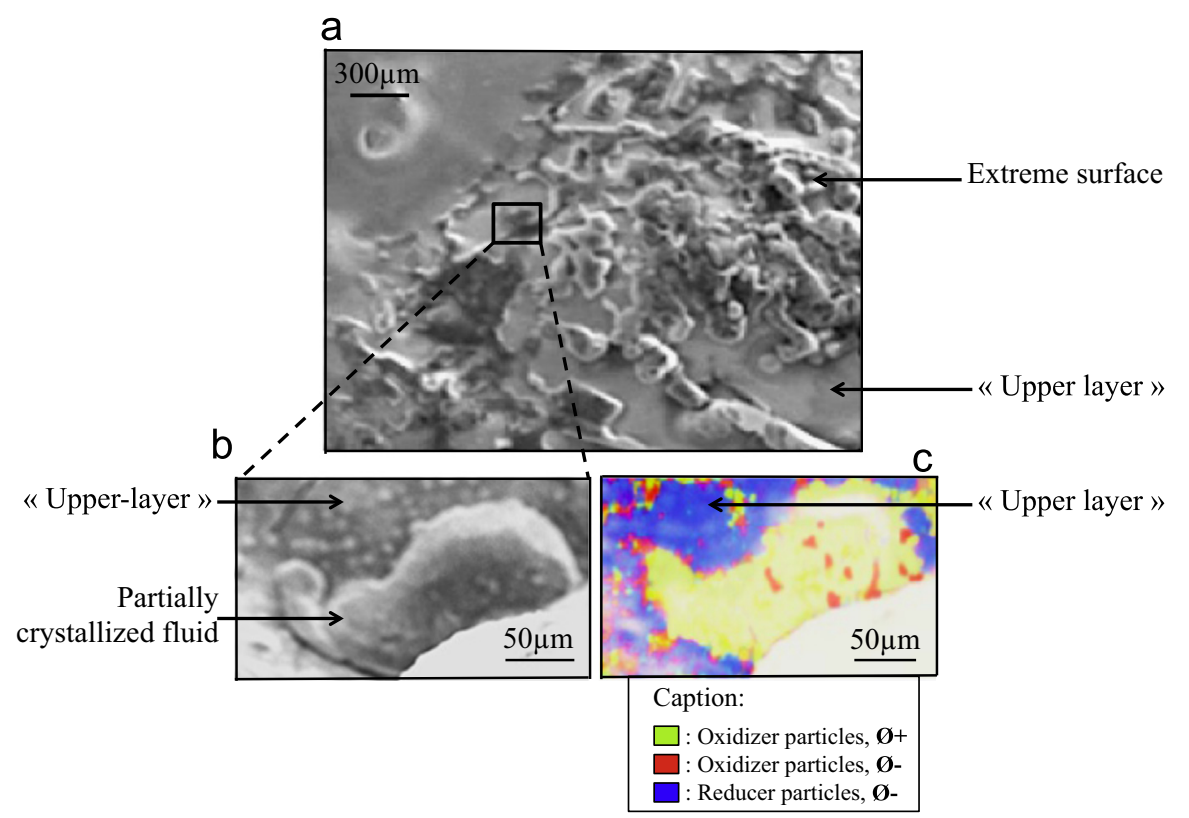

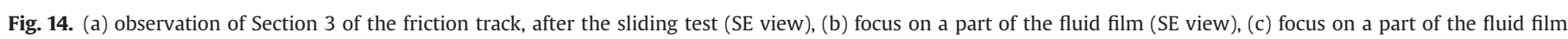
(EDX view).

observation: segregations and aggregations of particles. Using a cohesive interaction law, it is possible to reproduce such phenomena. Consequently, as proposed in previous works $[27,28]$ a cohesive unilateral contact law is used, involving the cohesion force $\gamma$ as a parameter. This cohesive law is combined with a Coulomb friction law to introduce tangential effects. 
In addition, in the experimental approach, the sapphire pin has the smoother first body surface of this study: $R_{\mathrm{a}}=0.4 \mu \mathrm{m}$. Thus, numerically, the contact between the third body particles and the walls is considered as a sliding contact with local adhesion phenomena between the particles, in order to take into account the Triplet 6 case of the experimental approach: Sapphire pin/solid propellant/striated porcelain plate.

To close this subsection, the value of the contact law parameters, i.e. the value of $\mu$, is needed to be determined.

In the experimental approach, on the TriboME device, the friction factor, $\mu$, without the third body, evolves according to the nature of the first bodies. The friction factor has the following values for the dry contacts:

- Steel/steel: from 0.15 to 0.3

- Porcelain/porcelain: from 0.5 to 0.6

- Sapphire/steel: from 0.05 to 0.2 .

Consequently, three different values are taken for $\mu: 0.01,0.5$, and 0.9 , and are combined with three different cohesion $\left(F_{\mathrm{adh}}\right)$ values: $0.01,0.5,0.9 \mathrm{~N}$. Such variation of the cohesion implicitly characterizes variations in properties of the third body particles (surface energy for example).

\subsection{Numerical model}

To reproduce the experimental setup, a bi-dimensional numerical model is used. As Atomic Force Microscope tests are on the way to determine the Young modulus of each third body particle, all of these are considered as rigid disks. The third body particles are represented by 12,500 elements and are distinguishable due to their diameter and colour in the contact:

- the reducer solid components are blue-coloured: the smaller disks,

- the oxidizer solid components are green-coloured: the intermediate disks,

- the nitramine solid components are red-coloured: the larger disks.

As the experimental tests, the initial thickness of the third body particles is equal to $400 \mu \mathrm{m}$ and the simulations are performed in two steps. First, the internal rigid disks are compressed between the two first bodies symbolised by two rough walls. The normal compression force applied on the upper rough-wall is equal to $353 \mathrm{~N}$, as the experimental tests. Then the shearing starts with a linear velocity of $60 \mathrm{~mm} \mathrm{~s}^{-1}$. During the experimental tests, the solid propellant's internal phenomena mainly occurred within the Section 2 of the friction track, where the linear velocity of the TriboME device is at its maximum $\left(V_{Y}=66 \mathrm{~mm} \mathrm{~s}^{-1}\right)$. Therefore it is wise to use an equivalent value in the numerical model, Figs. 15 and 16.

\subsection{Result discussion and comparisons}

\subsubsection{Segregation of particles during the shearing calculation}

During simulations, observations are focused on the solid particles motions. As the external stresses (temperature, tangential and normal forces...) are not modified between each friction test, these motions change according to the value of the previously defined parameters: local friction factor and cohesion values.

With the following pictures, the local stress $S_{N}$, endured by a particle " $i$ " from its first neighbours " $j$ " ( $L_{c}$ : contact list of the particle " $i$ "), is observed, Fig. 17:

$S_{N}^{i}=\sum_{j \in L_{c}(i)} r_{n}^{i j}$, with $r_{n}$ the local normal contact for the particle " $i$ "

As a consequence, the less a particle endures stresses from its neighbours, the more it turns blue. However, the more a particle endures stresses from its neighbours, the more it turns pink in the following pictures.

The first simulation presents third body particles sheared with intermediate values for local friction factor and cohesion $\left(F_{\mathrm{adh}}=0.5\right.$ and $\mu=0.5$ ), Figs. 18 and 19:

Fig. 18 shows that the larger particles are the ones that transmit the stresses within the third body thickness. Such observations match with results obtained on granular material with larger size of particles. Moreover, the shearing of the solid propellant gives birth to porosity next to the larger particles.

Numerically, the cohesion has a direct influence on the smaller particles. As the cohesion $\left(F_{\text {adh }}\right)$ is considered as a breaking force between particles, it is more efficient for smaller effective radius. This phenomenon exists from an experimental point of view as the Upper and Lower layers are compact and only composed of the smaller particles in the contact.

Fig. 19 shows the evolution of the distribution of the larger oxidizer particles within the third body thickness [23] during the friction simulation. The third body thickness is divided into 3 layers:

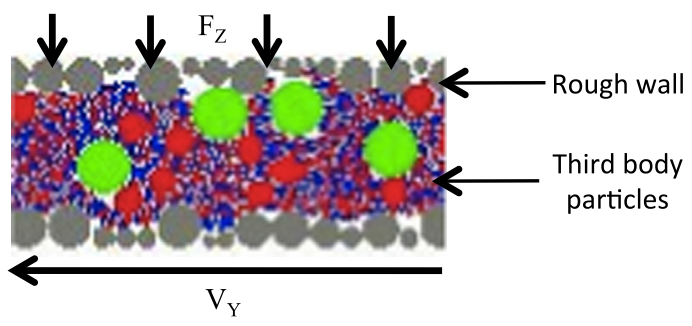

Scale: $\underline{0.7 \mathrm{~mm}}$

Fig. 16. Focus on the third body particles.

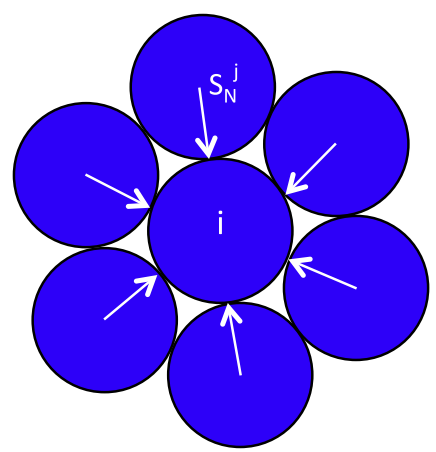

Fig. 17. Diagram of a particle $i$ enduring local stresses $S_{N}^{j}$ from its neighbours.

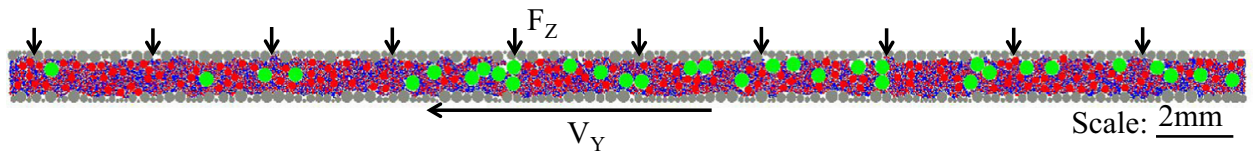

Fig. 15. Numerical model used for DEM simulation of the solid propellant friction test. 
- the layer 1 is the lower-layer

- the layer 2 is the intermediate-layer

- the layer 3 is the upper-layer

Thus, the larger particles tend to move to the centre of the third body thickness, contrary to a proportion of the smaller particles that tends to rise to extreme surface of the third body and a proportion tends to "dive" to the lower part of the third body thickness. This phenomenon matches the observations of the experimental approach. This is the segregation between the solid components, Seg solid/solid.

\subsubsection{Influence of local parameters on the global behaviour of the} particles flow

The second simulation presents third body particles sheared with intermediate local friction factor values $(\mu=0.5)$ and high cohesion values $\left(F_{\text {adh }}=0.9\right)$ :

Fig. 19 shows that the cohesion values between third body particles have a direct influence on the size of the porosities: the higher the cohesion values are, the larger the porosities are.

The evolution of the distribution of larger oxidizer particles within the third body thickness during the friction simulation is the same as observed previously. Indeed, the $\operatorname{Seg}_{\text {solid/solid }}$ takes place also here, (Fig. 19)

The third simulation presents third body particles sheared with intermediate local friction factor values $(\mu=0.5)$ and low cohesion values $\left(F_{\text {adh }}=0.01\right)$ :

Fig. 20 shows that with low values of cohesion between the third body particles, there was no porosity within the thickness in nominal mode. Moreover, shocks between larger particles give birth to internal porosity within the third body particles. In addition, wedging between larger particles and the peak of roughness on a wall increases the local stresses undergone by the larger particles.

During this third friction simulation, the evolution of the distribution of larger oxidizer particles within the third body thickness is the same as observed previously. Indeed, the Seg solid/ solid takes place also here (Fig. 21).

The fourth simulation presents third body particles sheared with high local friction factor values $(\mu=0.9)$ and intermediate cohesion values $\left(F_{\mathrm{adh}}=0.5\right)$ :

Fig. 22 shows that shocks between larger particles and a peak of roughness of a wall, next to porosity, increases the local normal stresses undergone by the larger particles to their maximum values $\left(F_{Z \text { max }}=15000 \mathrm{~N}\right)$.

As for the three previous simulations, the $\mathrm{Seg}_{\text {solid/solid }}$ takes place also here, with larger oxidizer particles moving from the upper and lower layers to intermediate-layer.

The fifth simulation presents third body particles sheared with low local friction factor values $(\mu=0.1)$ and intermediate cohesion values $\left(F_{\text {adh }}=0.5\right)$ :

Fig. 23 shows that: lower friction factor values give birth to lower sized porosities within the third body thickness than the four previous simulations.

As for all the previous simulations, the $\operatorname{Seg}_{\text {solid/solid }}$ takes place also here, with larger oxidizer particles moving from the Upper and Lower layers to Intermediate-layer.

It is shown in this subsection that the adhesion force between particles is considered as a cohesion parameter in the third body flow. Thus, this local parameter has a direct influence on the global behaviour of the particles within the contact.

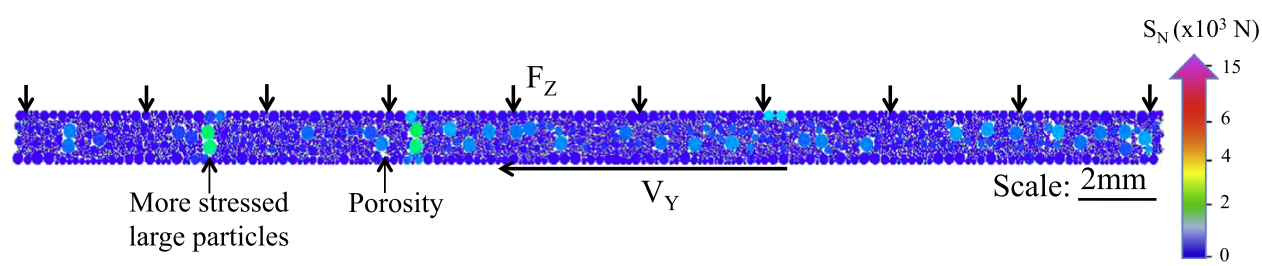

Fig. 18. Stresses applied by friction to third body particles, with intermediate values for local friction factor and cohesion.

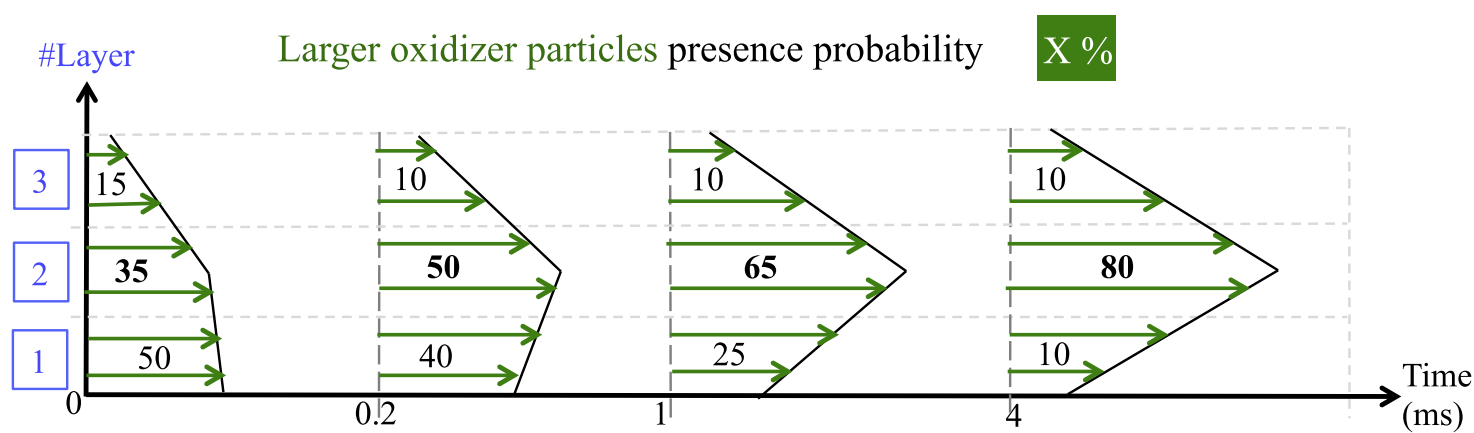

Fig. 19. Evolution of the distribution of larger oxidizer particles during the friction simulation, with intermediate values for local friction factor and cohesion.

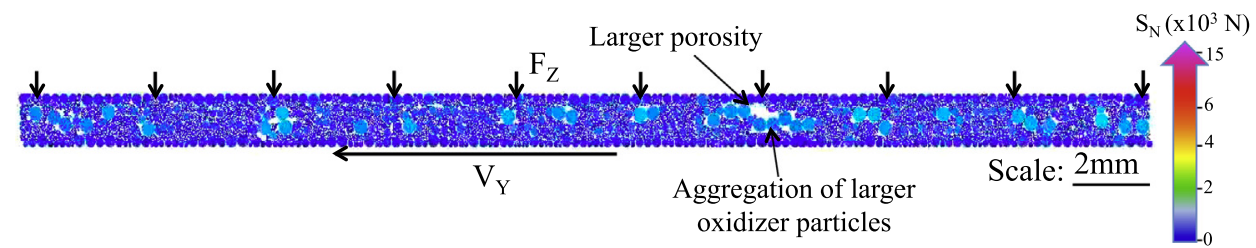

Fig. 20. Stresses applied by friction to third body particles, with intermediate values for local friction factor and high cohesion values. 


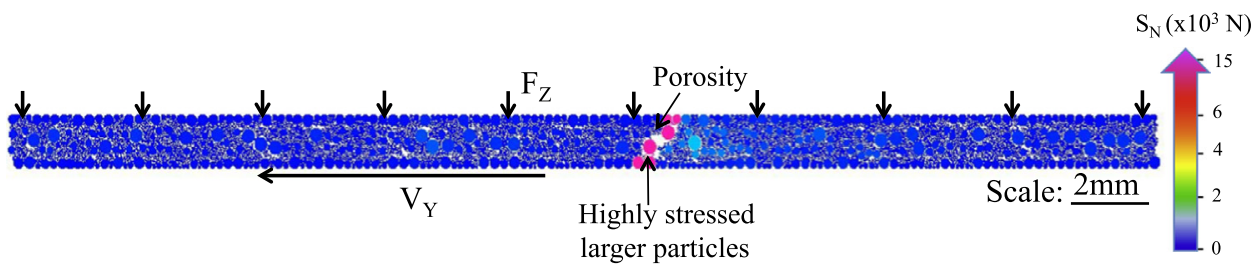

Fig. 21. Stresses applied by friction to third body particles, with intermediate values for local friction factor and low cohesion values.

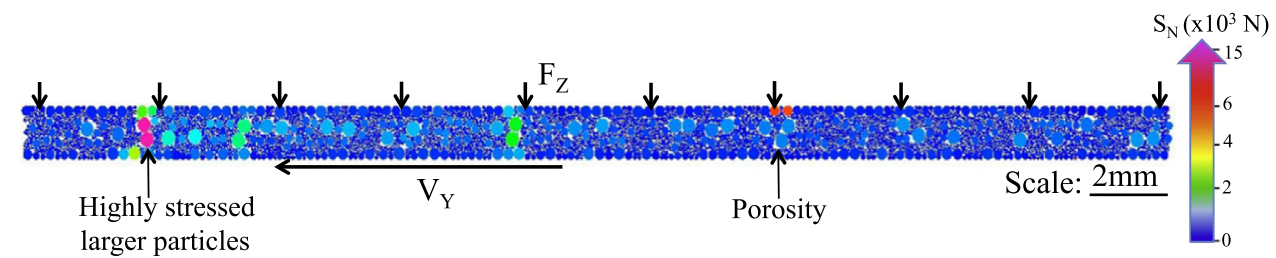

Fig. 22. Stresses applied by friction to third body particles, with high values for local friction factor and intermediate cohesion values.

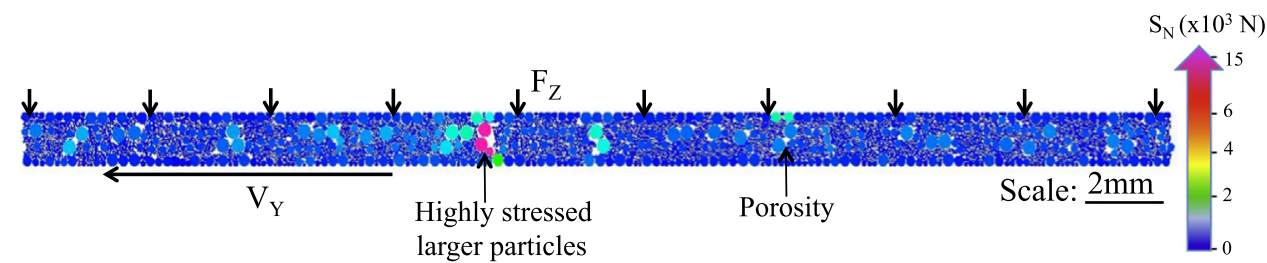

Fig. 23. Stresses applied by friction to third body particles, with low values for local friction factor and intermediate cohesion values.

\subsection{Conclusions on the numerical approach}

The numerical approach of the friction test of third body particles between two rough walls shows that the larger particles transmit the normal stresses through the thickness. Plus, the shearing tends to create the $\mathrm{Seg}_{\text {solid/solid }}$ phenomenon in the third body thickness (stratification in three distinctive layers of the third body thickness) and give birth to some porosity, i.e. a discontinuous flow of particles occurs. Nevertheless, by modifying some local factors, decreasing the adhesion force and the local friction factors between particles, it is possible to obtain a continuous flow of particles served with high local normal force value. This high value of the local normal forces is only observed for the interactions between large particles, next to porosity and at peaks of roughness on the first bodies, for very short time: $t=1 \times 10^{-4} \mathrm{~ms}$.

\section{General conclusions}

With the ultimate target being to understand the solid propellant ignition under friction conditions, two different approaches have been established. The experimental one lead to instrument a linear tribometer, called TriboME, in order to observe and analyse solid propellant ignitions. By means of the infrared and visible high-speed recording cameras, localised and generalised ignitions were observed. Plus, regarding the friction factor evolution during the friction test, it is clear that the solid propellant ignition is not directly linked to the friction factor value but to its evolution. Indeed, important fluctuations are observable within two distinctive sections of the friction track during which high peaks of temperature and generalised ignitions were recorded. These fluctuations of the friction factor value indicate that internal phenomena occur within the solid propellant volume. Due to Scanning Electron Microscopy analysis, three specific behaviours of the solid propellant are discovered during the friction test: the

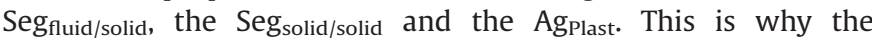
numerical approach of the solid propellant ignition under friction conditions makes sense. Not only confirming the $\operatorname{Seg}_{\text {solid/solid, the }}$ Discrete Element Method shows that specific localised interactions between some components occurs in the solid propellant thickness, i.e. low adhesion force between particles lead to more continuous particles flow and a decrease of the porosity size. These two local phenomena directly influence the normal forces locally undergone by specific particles, by increasing it significantly. Linked with the experimental approach, this high value of the local normal forces endured by the larger particles is seen as the first local initiator of the solid propellant ignition under friction conditions.

\section{Acknowledgements}

The authors want to thank the companies HERAKLES and FLIR, and The Montpellier University for their technical and financial support.

\section{References}

[1] Davenas A, et al. Technologie des propergols solides. Masson; 1989.

[2] Dickson P. Frictional heating and ignition of energetic materials. Los Alamos, New Mexico, USA: Los Alamos National Laboratory; 2005.

[3] Lengelle, et al. Ignition of solid propellants. Rech Aerospace 1991:2:1-20.

[4] Henson, BF, Asay, BW, Smilowitz, LB, Dickson, PM., Ignition chemistry in HMX from thermal explosion to detonation. In: Proceedings of the Shock compression of condensed matter-2001, AIP conference, vol. 620, Bethlehem, PA: American Institute of Physics; 2001. p. 1069-1072.

[5] Dyer, AS, Taylor, JW., Initiation of detonation by friction on a high explosive charge. In: Proceedings of the fifth Int. Symp. On Detonation, Pasadena, CA, USA; 1970. p. 291-300

[6] Bowden, FP, Gurton, OA., Nature, London, UK; 1948.

[7] Shoolderman, C., Processing of highly filled energetic compositions-simulation of a double co-rotating screw extruder and a complex die design, In: 33rd International annual conference of ICT TNO Prins Maurits Laboratory; 2002.

[8] Chapet, M, Vergnes, B, Techniques de l'Ingénieur, Réf: AM3653; 2001.

[9] Chounet, G, Nguyen, C, Guengant, Y, Marraud, C., Characterisation and 3D fluid flow modelling of propellant slurry in mixing equipments, SNPE Matériaux Energétiques; 2011. 
[10] AFNOR NF T 503 70: Epreuve de sensibilité au frottement, SNPE Matériaux Energétiques.

[11] Aidanpää J-O, Shen HH, Gupta RB. Experimental and numerical studies of shear layers in a granular shear cell. J Eng Mech 1998;122(3):187-96.

[12] Snyder LR, Kirkland JJ, Dolan JW. Introduction to modern liquid chromatography. John Wiley \& Sons; 2009.

[13] Funfschilling, C, Berdin, C, Quidot, M, Aubry, D., Micromechanical approach for modelling mechanical properties and damage of energetic materials, SNPE Matériaux Energétiques, Laboratory MSSMAT, CRNR-ECP; 2005.

[14] Berthier Y. Third-body reality-consequences and use of the third-body concept to solve friction and wear problems. John Wiley \& Sons, Ltd; 2005 (Chap12).

[15] Fenistein D, et al. Universal and wide shear zones in granular bulk flows. Phys Rev Lett 2004;92:094301.

[16] Brisset F. Microscopie électronique à balayage et microanalyses. EDP Sciences; 2008.

[17] Renouf M, Massi F, Fillot N, Saulot A. Numerical tribology of dry contact. Tribol Int $2011 ; 44(7-8): 834-44$.

[18] Azema E, Radjaï F. Stress-strain behaviour and geometrical properties of packing of elongated particles. Phys Rev E: Stat Nonlinear Soft Matter Phys 2010;81(5).

[19] Ciao CC, Hsiau SS. Influence of interstitial fluid viscosity on transport phenomena in sheared granular materials. Chem Eng Sci 2009;64:2562-9.
[20] Renouf M, Cao HP, Nhu VH. Multiphysical modeling of third-body rheology. Tribol Int 2011;44:417-25.

[21] Zuo QH, Addessio FL, Dienes JK, Lewis MW. A rate-dependent damage model for brittle materials based on the dominant crack. Int J Solids Struct 2006;43:3350-80.

[22] Dienes JK, Zuo QH, Kershner JD. Impact initiation of explosives and propellants via statistical crack mechanics. J Phys Mech Solids 2006;54(6):1237-75.

[23] Voivret C, Radjai F, Delenne J-Y, El Youssoufi MS. Multiscale force networks in highly polydisperse granular media. Phys Rev Lett 2009;102:178001.

[24] Moreau JJ. Some numerical methods in multibody dynamics: application to granular materials. Eur J Mech A Solids 1994;13(4-suppl.):93-114.

[25] Jean M. The non-smooth contact dynamics method. Comput Methods Appl Mech Eng 1999;177(3-4):235-57.

[26] Renouf M, Dubois F, Alart P. A parallel version of the non smooth contact dynamics algorithm applied to the simulation of granular media. J Comput Appl Math 2004;168(1-2):375-82.

[27] Richard D, Iordanoff I, Renouf M, Berthier Y. Thermal study of the dry friction contact with third body presence. J Tribol 2008;130(3):031404.

[28] Iordanoff I, Seve B, Berthier Y. Solid third body analysis using a discrete approach: influence of adhesion and particle size on macroscopic properties. J Tribol 2002;124(3):530. 